\title{
A NEW SPECIES OF BLEPHAROCERA FROM MASSACHUSETTS (DIPTERA)
}

\author{
By O. A. JohanNSEN,
} Ithaca, N.Y.

\section{Blepharocera similans n. sp.}

o. Head dark brown including antennæ, palpi a little paler. Face one-third as wide as head, front one-third wide as face. These measurements are based on a relaxed specimen. The area of enlarged facets about as with $B$. tenuipes. Antenna twice, the palpus as long as the width of the head. Fifteenth antennal segment a fifth longer than the fourteenth; last palpal segment slender, and three times as long as the penultimate. Thorax yellow including scutellum; the mesonotum shining brown with a purplish tinge and only faintly pollinose, the median space in front of scutellum with a pearly lustre; anterior part of pleura, brown. Abdomen brown, somewhat shining, posterior segments and hypopygium darker; venter yellow anteriorly; narrow posterior margins of the first two or three tergites paler. Structure of the hypopygium closely resembles that of $B$. tenuipes. See Kellogg's figure 2, plate 22, in the Proceedings of the California Academy of Sciences, 1903. In this figure the lateral lobes of the dorsal plate have parallel sides, their caudal margins squarely truncate, with the outer posterior angle of the lobe acute, the inner one right angled and the median tooth small. In my specimens of $B$. tenuipes the median tooth on the caudal margin of the lateral lobes of the dorsal plate is more conspicuous than that figured by Kellogg and with the apex directed slightly mesad. The lobe in the new species, $B$. similans, is relatively longer and the inner angle wholly wanting, the inner margin of the lobe gradually curving from the median tooth toward the base of the lobe. The claspers of $B$. similans are slightly more 
curved than in B. tenuipes. Legs brown, slender, middle femur a tenth longer than the fore femur; tibiæ and comsponding tarsal segments of fore and middle legs subequal, the measurements for the middle leg beginning with the femur being $2.8,2.4,1.4,0.6,0.4,0.25,0.25 \mathrm{~mm}$. Hind legs wanting in the type specimen. Wing clear hyaline, iridescent; length from basal articulation, $4.5 \mathrm{~mm}$. Halteres yellow with brown knob. Length of fly $4 \mathrm{~mm}$. Amherst, Massachusetts, June 25, 1927. Dr. C. P. Alexander, Collector.

Aside from the difference in the form of the hypopygium as noted above, this fly differs from $B$. tenuipes in having a distinctly shining thorax, in the proportion of its tibia to basitarsus being 12 to 7 instead of 12 to 6 , in the sides of the face being more nearly straight and in the hairs on the base of the claws being less conspicuous.

I am indebted to Mr. F. W. Edwards for submitting this fly to me for description. Several specimens in the British Museum, type in the Cornell University collection. 

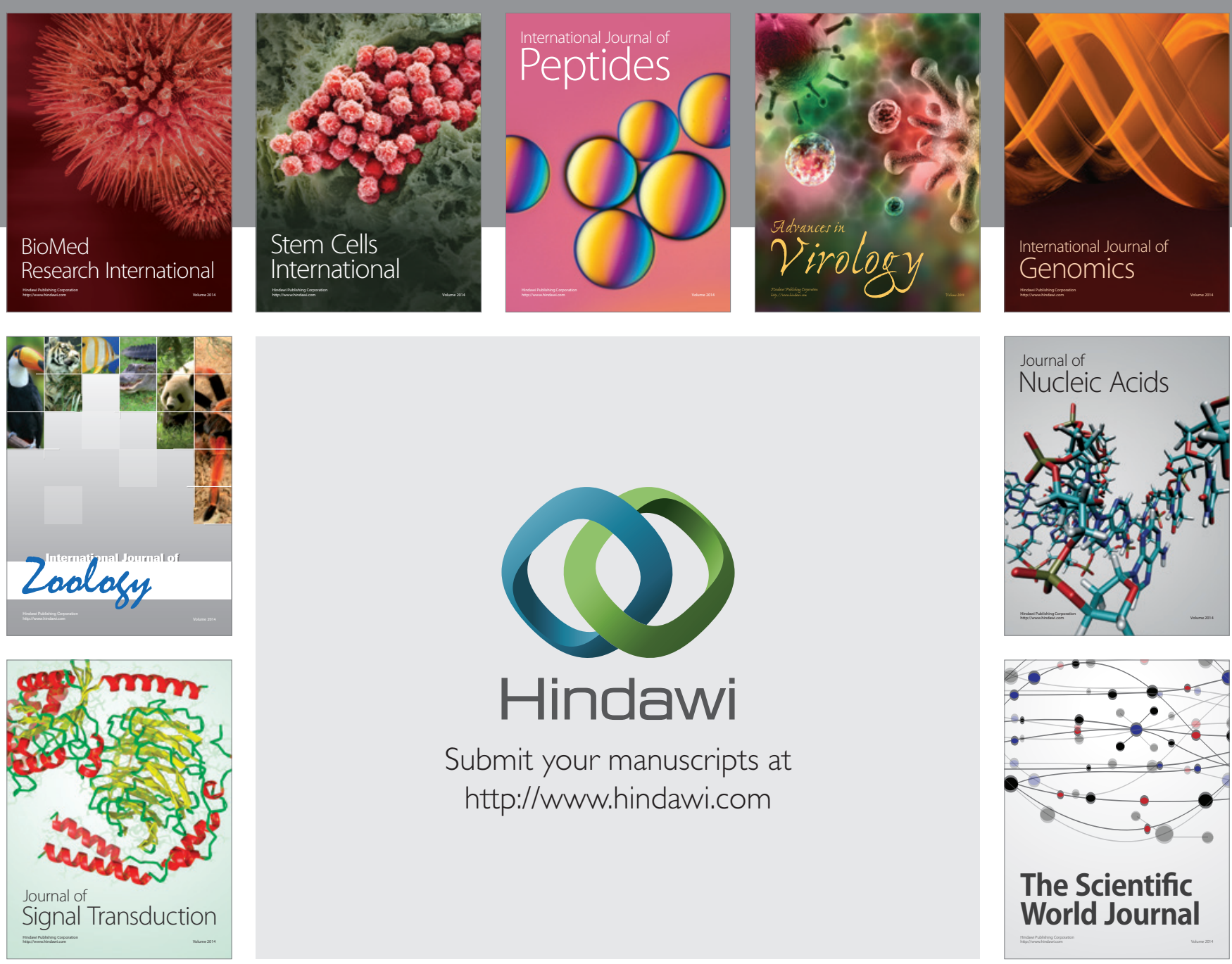

Submit your manuscripts at

http://www.hindawi.com
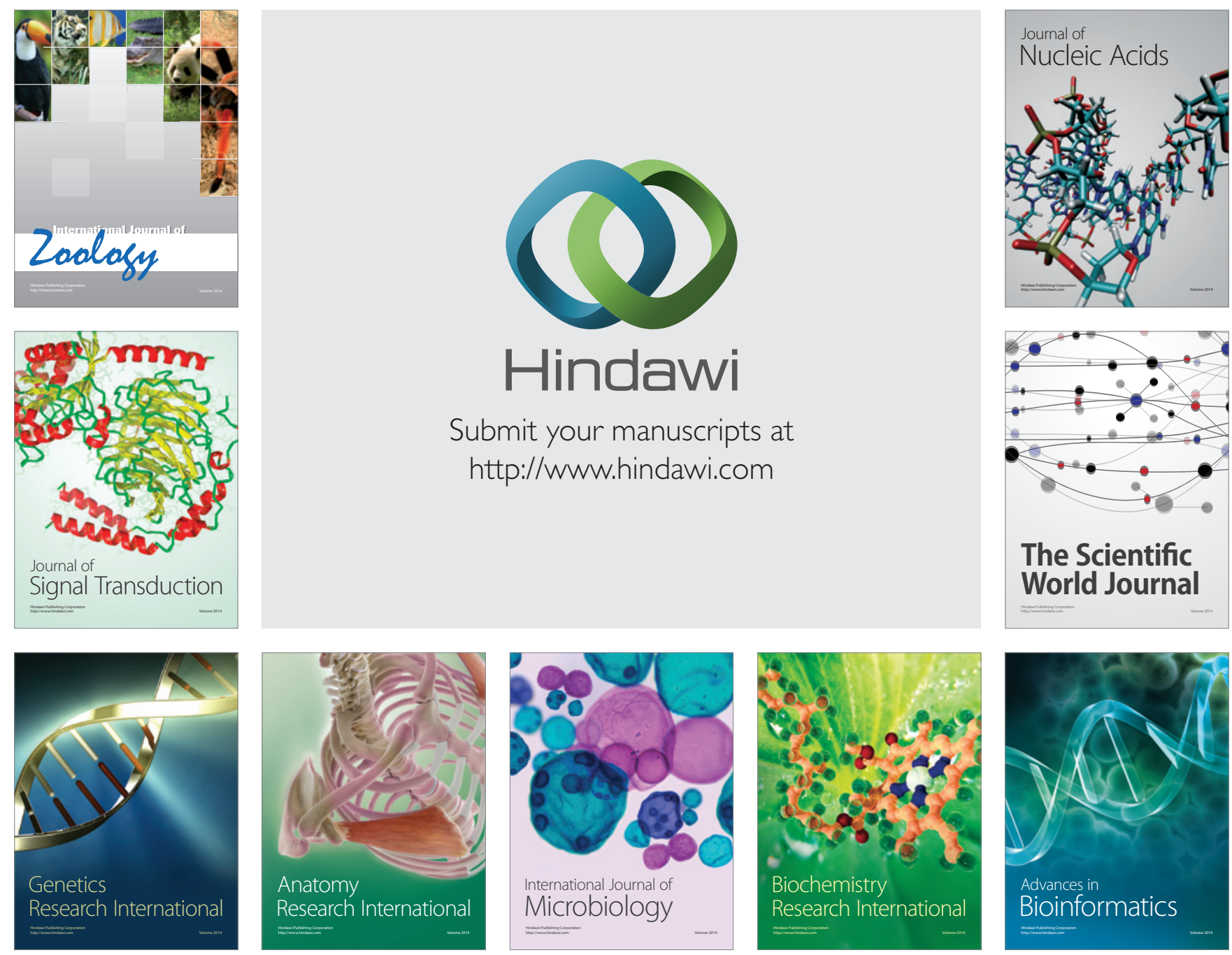

The Scientific World Journal
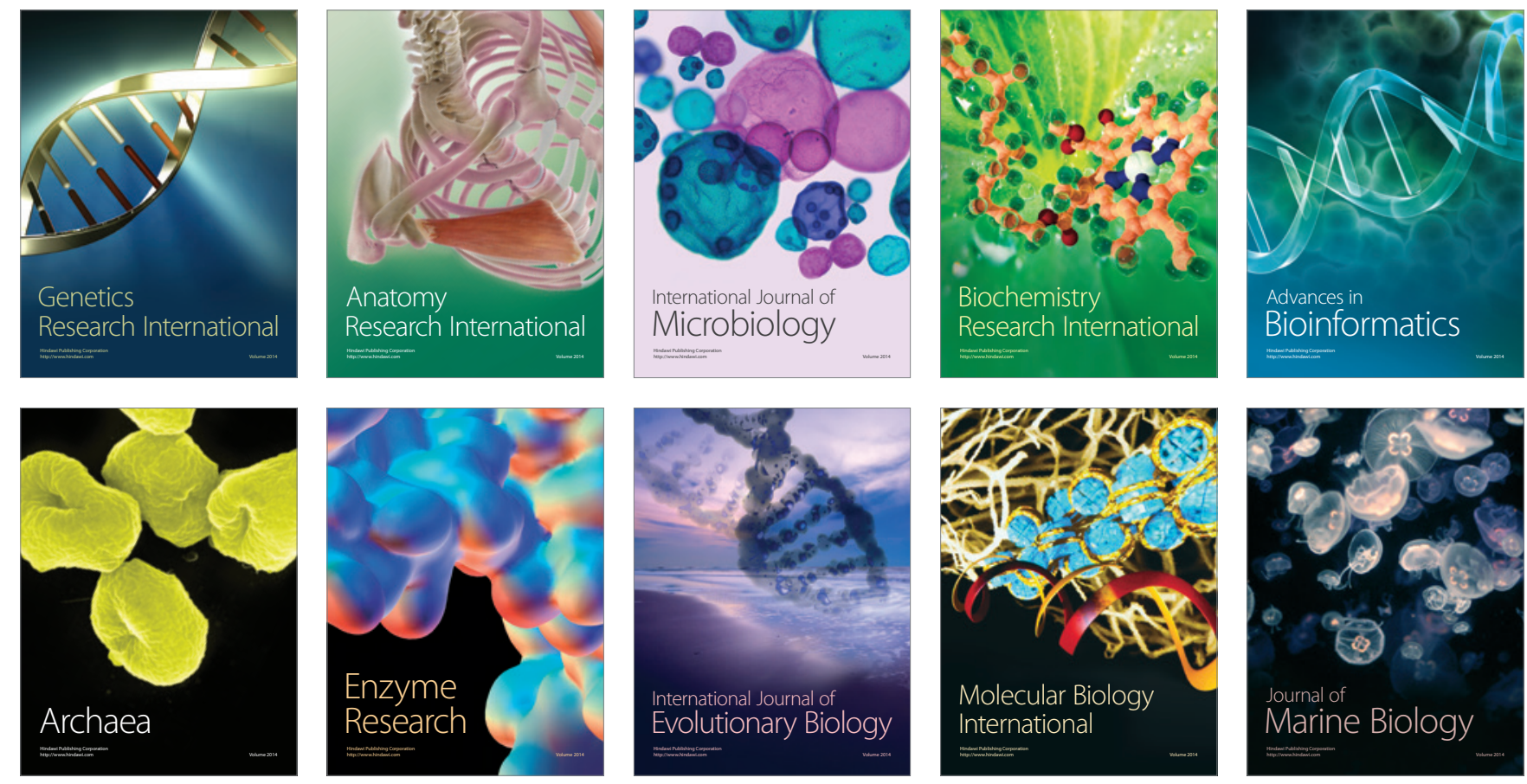